\title{
The effect of the Megamix preparation and complex mineral fertilizers on germination and photosynthetic productivity of spring wheat
}

\author{
Vitaly Isaychev, Nikolay Andreev*, and Vladimir Kostin \\ Ulyanovsk State Agrarian University, 432017 Ulyanovsk, Russia
}

\begin{abstract}
The method of presowing and foliar treatment of spring wheat crops with various growthregulating preparations should be referred to a number of promising techniques that provide increased productivity and quality of crop production. The conducted studies have shown that the highest values of germination energy and laboratory germination during presowing treatment of seeds with experimental preparations were found in the option Megamix-zinc. The use of various modifications of the Megamix preparation for presowing seed inoculation contributes to an increase in the field germination of the experimental crop according to all options, depending on the year of the study. On average, over the years of the research, the used modifications of the Megamix preparation and their combination with mineral fertilizers contribute to an increase in productivity by $0.51-3.23 \mathrm{~kg} / \mathrm{ha}$, the best result over control is ensured by the use of the Megamix-zinc modification compared to complex sulfur-containing mineral fertilizers, which is $11.83 \%$. Thus, the use of experimental preparations and their combinations with complex mineral fertilizers has a positive effect on production processes which ultimately contributes to an increase in the productivity of spring wheat.
\end{abstract}

\section{Introduction}

Ulyanovsk oblast is the largest part of the Volga region that produces commodity grain of soft spring wheat. However, wheat yields in the region are relatively low and unstable. One of the main reasons for this is the poor quality of the seed material due to cultivation of this crop without balanced mineral nutrition in soils with a low content of trace elements. The presowing and foliar treatment of spring wheat crops with various modifications of the Megamix preparation (Megamix profi, Megamix-nitrogen, Megamix-zinc) should be referred to the promising methods that provide a further increase in the yield and quality of plant products.

This task is of great importance because in practical crop production it is important to find ways to increase the productivity of plants, improve their quality indicators, and their resistance to various adverse environmental factors.

At present, the studies are under way due to incomplete study of the effect of the Megamix preparation and complex sulfur-containing mineral fertilizers on physiological and biochemical processes, in particular on laboratory germination, field germination, seed growth and seed germination energy, dry matter accumulation, growth of phytomass and net photosynthetic productivity of the soft spring wheat variety "Ulyanovskaya $100 "$.

\section{Materials and methods}

The studies were conducted in laboratory and field conditions of P.A. Stolypin Ulyanovsk State Agrarian University. The experimental crop was spring wheat of the "Ulyanovskaya 100" variety. The technique of conducting the field experiment was that generally accepted for small plots, the replication was fourfold, the arrangement of options in the experiment was randomized, the plot area was $20 \mathrm{~m}^{2}$. The objects of research were the following: various modifications of the Megamix preparation (Megamix - profi, Megamixnitrogen, Megamix-zinc) and complex mineralcontaining sulfur fertilizer diammofoska $\mathrm{N}_{15} \mathrm{P}_{15} \mathrm{~K}_{15} \mathrm{~S}_{10}$. Before sowing, the seeds were treated with growth regulators. When the tillering phase came, foliar treatment of the crops with the studied preparations was carried out at the concentrations recommended by the manufacturer. The application of experimental preparations can be carried out simultaneously with the use of herbicides in the amount of 200 liters of working solution per 1 ha or as a separate technological operation. In the field experiment, there were two types of fertility: type 1 - natural fertility, type 2 - with the application of experimental mineral fertilizers.

The soil of the experimental field is leached black soil of medium thickness, medium loamy soil with the following agrochemical characteristics: humus content

* Corresponding author: andreev919@yandex.ru 
$4.3 \%$ (medium humus soil), $\mathrm{pH}$ 5.8-6.8 (slightly acid), the content of mobile phosphorus and potassium, $107-142$ and $103-135 \mathrm{mg} / \mathrm{kg}$ of soil respectively (increased), the degree of base saturation is 96.4-97.9\%, the amount of absorbed bases is 25.5-27.8 $\mathrm{mg}$ equivalent/per $100 \mathrm{~g}$ of soil.

Meteorological conditions over the years of the study were different in temperature and soil moisture conditions which allowed us to study comprehensively the effect of the factors used.

\section{Research results}

Plant growth regulators, their artificial analogs or compositional preparations, which contain a balanced complex of phytoregulators, biologically active substances, microelements make it possible to purposefully control the most important processes of plant growth and development, and effectively use the potential capabilities of plants [1-4].

Germination energy is the percentage of germinated seeds over a definite period. It characterizes the ability of seeds to produce even germination in the field which means good standing and survival of plants.

Laboratory germination is the main indicator of sowing qualities of seeds, determining their physiological condition. Laboratory germination of seeds is understood as the number of standardly germinated seeds for a certain period (mainly 7-10 days) in a sample taken for analysis. It gives a better understanding of the real possibility of obtaining seedlings of plants in the field.

The conducted studies have shown that the highest values of germination energy and laboratory germination during pre-sowing treatment of seeds with experimental preparations were seen in the option of Megamix-zinc. Germination energy was $89.6 \%$ (2018), $89 \%$ (2019), laboratory germination was $97.5 \%$ (2018) and $97.8 \%$ (2019) (Table 1).

Table 1. The effect of various modifications of the Megamix preparation on germination energy and laboratory germination of the spring wheat variety "Ulyanovskaya 100", (average over the years of research)

\begin{tabular}{|c|c|c|}
\hline Option & $\begin{array}{c}\text { Germination } \\
\text { energy, \% }\end{array}$ & $\begin{array}{c}\text { Laboratory } \\
\text { germination, \% }\end{array}$ \\
\hline Control & 83.5 & 91.9 \\
\hline Megamix-profi & 84.9 & 93.9 \\
\hline $\begin{array}{c}\text { Megamix- } \\
\text { nitrogen }\end{array}$ & 88.6 & 95.8 \\
\hline Megamix-zinc & 89.3 & 97.7 \\
\hline
\end{tabular}

Field germination is the number of emerged seedlings, expressed as a percentage of the number of seeds germinated. Numerous factors influence field germination: the soil-climatic conditions of the zone, soil properties, meteorological conditions, biological characteristics of crops, diseases and pests, seed quality, level of agricultural technology and farming practices.

The results obtained show that the use of various modifications of the Megamix preparation for presowing seed inoculation contributes to an increase in field germination of the experimental crop in all cases depending on the year of the study. The highest value at $80 \%$ was found in the option Megamix - zinc, the lowest one is $71.4 \%$, which was found in the control option. Both values were obtained in 2019 which was characterized by unfavorable weather and climatic conditions during the seed germination period, which proves the effectiveness of the experimental preparations under stressful conditions for seeds (Table 2).

Table 2. The effect of various modifications of the Megamix preparation on field germination of the spring wheat variety

"Ulyanovskaya 100", (average over the years of research)

\begin{tabular}{|c|c|}
\hline Option & Field germination, \% \\
\hline Control & 72.2 \\
\hline Megamix-profi & 74.4 \\
\hline Megamix-nitrogen & 77.6 \\
\hline Megamix-zinc & 79.6 \\
\hline
\end{tabular}

The growth vigor of seeds is the potential ability of seeds to rapidly germinate and form strong seedlings. It largely characterizes the ability of seeds to germinate in the field and the degree of their subsequent development.

From the data of table 3 one can see that the maximum length of germinal seedlings $(4.75 \mathrm{~cm})$ and germinal roots $(8.01 \mathrm{~cm})$ was in the option of Megamixzinc.

Table 3. The effect of various modifications of the Megamix preparation on the growth vigor of seeds of the spring wheat variety "Ulyanovskaya 100", (average over the years of research)

\begin{tabular}{|c|c|c|}
\hline Option & $\begin{array}{c}\text { Length of } \\
\text { germinal } \\
\text { seedlings, cm }\end{array}$ & $\begin{array}{c}\text { Length of } \\
\text { germinal } \\
\text { roots, cm }\end{array}$ \\
\hline Control & 4.04 & 7.20 \\
\hline Megamix-profi & 4.22 & 7.52 \\
\hline Megamix-nitrogen & 4.42 & 7.74 \\
\hline Megamix-zinc & 4.72 & 7.97 \\
\hline
\end{tabular}

Table 4. The effect of various modifications of the Megamix (M) preparation on the accumulation of dry matter in spring wheat plants of the variety "Ulyanovskaya 100", kg/ha, (average over the years of research)

\begin{tabular}{|c|c|c|c|}
\hline \multicolumn{4}{|c|}{ Growth and development phases } \\
\hline Tillering & Shooting & $\begin{array}{c}\text { Ear } \\
\text { formation }\end{array}$ & $\begin{array}{c}\text { Milky } \\
\text { ripeness }\end{array}$ \\
\hline \multicolumn{4}{|c|}{ Variant Control } \\
\hline 416.42 & 2079.86 & 4101.225 & 5507.41 \\
\hline \multicolumn{4}{|c|}{ Variant Megamix-profi } \\
\hline 428.04 & 2125.035 & 4236.875 & 5861.87 \\
\hline \multicolumn{4}{|c|}{ Variant Megamix-nitrogen } \\
\hline 434.425 & 2130.86 & 4239.88 & 5810.515 \\
\hline \multicolumn{4}{|c|}{ Variant Megamix-zinc } \\
\hline 437.515 & 2160.715 & 4302.81 & 6039.605 \\
\hline \multicolumn{4}{|c|}{ Variant Megamix-profi + NPKS } \\
\hline 439.81 & 2207.555 & 4402.685 & 6175.975 \\
\hline 445.44 & Variant Megamix-nitrogen+ NPKS \\
\hline 451.05 & 2220.075 & 4450.35 & 6204.605 \\
\hline 457.53 & 2245.555 & 4523.56 & 6261.92 \\
\hline \multicolumn{4}{|c|}{} \\
\hline \multicolumn{4}{|c|}{ Variant Megamix-zinc+NPKS } \\
\hline
\end{tabular}


Dry matter of plants is represented in $90-95 \%$ by organic compounds - proteins and other nitrogenous substances, carbohydrates (sugars, starch, fiber, pectin substances), fats, the content of which determines the quality of the yield. The accumulation of dry matter by plants is the final result of their interaction with environmental factors and allows us to make a judgement about the conditions of growth and development, responsiveness to farming practices.

The increased rate of dry matter accumulation in all phases of growth and development was observed in the option Megamix-zinc in 2018 with favorable weather conditions and previously fertilized soil. During the tillering phase it was $459.89 \mathrm{~kg} / \mathrm{ha}$, in the shooting period it was $2259.64 \mathrm{~kg} / \mathrm{ha}$, in the ear formation phase it was $4558.93 \mathrm{~kg} / \mathrm{ha}$, and in the phase of milky ripeness it was $6265.66 \mathrm{~kg} / \mathrm{ha}$. The application of mineral fertilizers had a positive effect on the increase in the dry matter accumulation by plants of the experimental crop (Table 4).

The results of the two year studies on the effect of various modifications of the Megamix preparation on the relative phytomass growth of spring wheat plants are shown in Table 5.

The data show that under the influence of the Megamix-zinc preparation applied together with the application of a complex mineral sulfur-containing fertilizer, there is a maximum increase in the phytomass growth rate on average over 2 years by $0.52 \mathrm{mg} / \mathrm{g}$ in the shooting phase, by $0.72 \mathrm{mg} / \mathrm{g}$ in the ear formation phase and by $0.56 \mathrm{mg} / \mathrm{g}$ in the phase of milky ripeness.

One of the indicators characterizing the production process of plants is the net photosynthetic productivity (NPP). This indicator is often used in scientific research to determine the photosynthetic activity of crops. The net photosynthetic productivity is the amount of dry matter in grams accumulated by $1 \mathrm{~m}^{2}$ of leaf surface in 1 day (Table 6).

Table 5. The effect of various modifications of the Megamix (M) preparation on the relative growth rate of phytomass of the spring wheat variety "Ulyanovskaya 100", mg/g per day for 10 plants, (average over the years of research)

\begin{tabular}{|c|c|c|c|}
\hline Option & Shooting & $\begin{array}{c}\text { Ear } \\
\text { formation }\end{array}$ & $\begin{array}{c}\text { Milky } \\
\text { ripeness }\end{array}$ \\
\hline Control & 2.17 & 4.62 & 3.88 \\
\hline Megamix-profi & 2.22 & 4.89 & 4.08 \\
\hline $\begin{array}{c}\text { Megamix- } \\
\text { nitrogen }\end{array}$ & 2.28 & 4.96 & 4.165 \\
\hline Megamix-zinc & 2.31 & 5.1 & 4.28 \\
\hline Control + NPKS & 2.33 & 5.12 & 4.305 \\
\hline $\begin{array}{c}\text { Megamix-profi + } \\
\text { NPKS }\end{array}$ & 2.41 & 5.13 & 4.395 \\
\hline $\begin{array}{c}\text { Megamix- } \\
\text { nitrogen+ NPKS }\end{array}$ & 2.45 & 5.22 & 4.42 \\
\hline $\begin{array}{c}\text { Megamix-zinc+ } \\
\text { NPKS }\end{array}$ & 2.69 & 5.34 & 4.44 \\
\hline
\end{tabular}

The maximum value of the NPP is observed in the option of Megamix-zinc with the application of complex mineral fertilizers, in the shooting phase $-9.52 \mathrm{~g} / \mathrm{m}^{2}$ (2018), in the ear formation phase $-13.88 \mathrm{~g} / \mathrm{m}^{2}$ (2018), in the phase of milky ripeness $-11.70 \mathrm{~g} / \mathrm{m}^{2}$ (2019).
Table 6. The effect of various modifications of the Megamix (M) preparation on NPP in spring wheat plants, $\mathrm{g} / \mathrm{m}^{2}$ per day, (average over the years of research)

\begin{tabular}{|c|c|c|c|}
\hline Option & Shooting & $\begin{array}{c}\text { Ear } \\
\text { formation }\end{array}$ & $\begin{array}{c}\text { Milky } \\
\text { ripeness }\end{array}$ \\
\hline Control & 9.08 & 12.83 & 10.19 \\
\hline Megamix-profi & 9.12 & 13.14 & 10.63 \\
\hline $\begin{array}{c}\text { Megamix- } \\
\text { nitrogen }\end{array}$ & 9.27 & 13.07 & 10.76 \\
\hline Megamix-zinc & 9.30 & 13.37 & 10.96 \\
\hline Control + NPKS & 9.29 & 13.37 & 11.26 \\
\hline $\begin{array}{c}\text { Megamix - profi } \\
\text { + NPKS }\end{array}$ & 9.36 & 13.32 & 11.32 \\
\hline $\begin{array}{c}\text { Megamix - } \\
\text { nitrogen+ NPKS }\end{array}$ & 9.45 & 13.49 & 11.44 \\
\hline $\begin{array}{c}\text { Megamix - zinc+ } \\
\text { NPKS }\end{array}$ & 9.50 & 13.72 & 11.65 \\
\hline
\end{tabular}

The yield of crops is the main factor that determines the volume of crop production. Therefore, much attention is paid to this indicator. The factors of the yield change are the following:

- environmental and climatic ones: soil fertility; soil texture; terrain relief; temperature condition; ground water level; rainfall, etc.;

- economic ones: quantity, quality and structure of fertilizers applied; the quality and terms of all field work; seed quality; a change in the varietal composition of crops; liming and gypsum application to the soil; the control of diseases and pests of plants; crop rotation in crop rotation fields, etc.

The crop yield, in addition to the abovementioned factors, depends on a number of other agrotechnical measures: the quality and methods of cultivating the soil, planting crops in the fields of crop rotation, methods and terms of tending crops, the use of biological and chemical means of crop protection, liming, gypsum application, etc. A significant resource for increasing production in crop production is to improve the structure of sown areas, i.e. an increase in the share of more productive crops in the total sown area. An important resource for increasing production of crops is to raise the return on fertilizers, which, in turn, depends on the dose and quality of fertilizers, their structure, terms and methods of application to the soil. An important resource for increasing production is preventing losses during harvesting.

Introduction of the most productive crops and varieties and improvement of the agricultural technology of their cultivation occupied the leading place among the most important resources for increasing the yield of agricultural crops. In plant growing, special attention has been paid recently to the introduction of technologies of applying physiological - biochemically active substances (liquid fertilizer mixtures of growthpromoting and growth-regulating nature) in the cultivation of agricultural crops including spring wheat.

The studies of many authors have shown a positive impact of such preparations on the production processes and productivity of many crops [5-8]. Yielding capacity is the main integral indicator of agricultural crops which directly demonstrates the effectiveness of various 
agricultural operations and is a fundamental measure in assessing the effect of various factors on field crops. In addition to genetic characteristics, in order to obtain steady good yields, it is necessary to provide the plants with nutrients as much as possible throughout the growing season. The intensity of the course of production processes in crops, and, as a consequence of this, the level of yielding capacity, largely depend on weather and climate conditions during the growing season.

The data obtained as a result of the studies show that the preparations used in the experiment with spring wheat and their combinations with complex mineral fertilizers significantly activate physiological biochemical and production processes, provide optimization of the mineral and air nutrition of spring wheat plants during ontogenesis. As a result of this, we observe an increase in the yield of the experimental crop.

Table 7. The effect of various modifications of the Megamix preparation (M) on the yield of the spring wheat variety "Ulyanovskaya 100" (2018-2019), c/ha

\begin{tabular}{|c|c|c|c|c|c|}
\hline \multirow{2}{*}{ Options } & \multicolumn{3}{|c|}{ Yield } & \multicolumn{2}{c|}{ Increase } \\
\cline { 2 - 6 } & $\mathbf{2 0 1 8}$ & $\mathbf{2 0 1 9}$ & Mean & c/ha & \% \\
\hline Control & 30.34 & 24.28 & 27.31 & - & - \\
\hline Megamix-profi & 30.79 & 24.85 & 27.82 & 0.51 & 1.87 \\
\hline $\begin{array}{c}\text { Megamix- } \\
\text { nitrogen }\end{array}$ & 32.00 & 25.12 & 28.56 & 1.25 & 4.58 \\
\hline Megamix-zinc & 32.85 & 25.50 & 29.18 & 1.87 & 6.85 \\
\hline Control + NPKS & 32.22 & 25.66 & 28.94 & 1.63 & 5.97 \\
\hline $\begin{array}{c}\text { Megamix-profi } \\
+ \text { NPKS }\end{array}$ & 32.40 & 25.90 & 29.15 & 1.84 & 6.74 \\
\hline $\begin{array}{c}\text { Megamix- } \\
\text { nitrogen+ NPKS }\end{array}$ & 32.41 & 26.42 & 29.42 & 2.12 & 7.73 \\
\hline $\begin{array}{c}\text { Megamix-zinc+ } \\
\text { NPKS }\end{array}$ & 34.10 & 26.98 & 30.54 & 3.23 & 11.83 \\
\hline LSD 05 & 1.53 & 0.50 & & & \\
\hline
\end{tabular}

The data obtained as a result of the studies show (Table 7) that the modifications of the Megamix preparation used in the experiment with spring wheat and their combination with complex mineral fertilizers activate metabolic processes.

As a result, the yield of the experimental crop increases. The studies have shown that on average over the years of research, the used modifications of the Megamix preparation and their combination with mineral fertilizers contribute to an increase in the yielding capacity by $0.51-3.23 \mathrm{c} / \mathrm{ha}$. The use of the modification Megamix-zinc shows the best result in relation to the control option with the application of complex sulfur-containing mineral fertilizers which is $11.83 \%$ (Table 7).

The amount of the formed yield of any grain field crop is made up of the following elements of the yield structure: the number of productive stems, plant height, spike length and weight of 1000 grains, the number of grains in an ear, and the weight of grain in an ear. As a rule, a higher grain weight is formed in years with low air temperature during the grain filling phase and a long period of grain formation. The fundamental factors that contribute to a better grain filling are the soil moisture and low air temperature which are extremely necessary during these phases of ontogenesis.

Table 8. The effect of various modifications of the Megamix (M) preparation on the elements of the yield structure of the spring wheat variety "Ulyanovskaya 100", (average over the years of research)

\begin{tabular}{|c|c|c|c|c|}
\hline $\begin{array}{c}\text { Plant } \\
\text { height, } \\
\text { cm }\end{array}$ & $\begin{array}{c}\text { Spike } \\
\text { length, } \\
\text { cm }\end{array}$ & $\begin{array}{c}\text { Number } \\
\text { of grains } \\
\text { per ear, } \\
\text { pcs. }\end{array}$ & $\begin{array}{c}\text { Grain } \\
\text { Weight } \\
\text { in an ear, } \\
\text { g. }\end{array}$ & $\begin{array}{c}\text { Weight } \\
\text { of 1000 } \\
\text { grains, } \\
\text { g. }\end{array}$ \\
\hline \multicolumn{5}{|c|}{ Variant Control } \\
\hline 70.92 & 9.36 & 25.00 & 0.80 & 33.55 \\
\hline \multicolumn{5}{|c|}{ Variant Megamix -profi } \\
\hline 72.43 & 9.70 & 26.20 & 0.84 & 34.00 \\
\hline \multicolumn{5}{|c|}{ Variant Megamix - nitrogen } \\
\hline 72.92 & 9.78 & 26.25 & 0.85 & 34.35 \\
\hline \multicolumn{5}{|c|}{ Variant Megamix - zinc } \\
\hline 73.37 & 9.86 & 26.35 & 0.90 \\
\hline \multicolumn{5}{|c|}{ Variant Control + NPKS } \\
\hline 73.63 & 9.86 & 26.70 & 0.91 & 35.75 \\
\hline \multicolumn{5}{|c|}{ Variant Megamix - profi + NPKS } \\
\hline 76.75 & 10.07 & 27.75 & 1.06 & 35.30 \\
\hline \multicolumn{5}{|c|}{ Variant Megamix - nitrogen+ NPKS } \\
\hline 78.35 & 10.14 & 28.05 & 1.07 \\
\hline \multicolumn{5}{|c|}{ Variant Megamix - zinc+NPKS } \\
\hline 78.61 & 10.21 & 28.26 & 1.10 & 35.90 \\
\hline
\end{tabular}

The spike productivity, that is, the number of grains in the ear and the weight of grain in the ear, also increased with the use of growth regulators and complex mineral fertilizers.

From the data given (Table 8) it follows that on average for 2018-2019 the height of plants and the spike length of spring wheat under the influence of the factors used increased compared to the control option by $1.51-7.69 \mathrm{~cm}$ and $0.34-0.85 \mathrm{~cm}$, respectively, depending on the option. Foliar treatment of spring wheat plants of the variety "Ulyanovskaya 100" with growth regulators has a positive effect on the weight of 1000 seeds. For 2018-2019, this indicator increased by $0.45-2.35 \mathrm{~g}$, compared with the control option. The maximum value was found in the option "Megamix-zinc + NPKS".

\section{Conclusions}

Thus, the use of experimental preparations and their combinations with complex mineral fertilizers has a positive effect on production processes which ultimately helps to increase the productivity level of spring wheat.

\section{References}

1. R.A. Borzenkova, M.P. Borovkina, M.Yu. Yashkov, Plant Physiol., 45(4), 549-556 (2001)

2. V.V. Vakulenko, The application of growth regulators in production of grain crops, Grain Econ. of Russ., 3, 36-38 (2013)

3. I.A. Gaisin, R.I. Safin, M.M. Ilyasov, M.Sh. Tagirov, Regulators of plant growth and development (Moscow, 1999), 168 p. 
4. M.I. Dulov, A.P. Trotz, Yield and grain quality of spring soft wheat in the forest-steppe zone of the Middle Volga region when applying resource-saving cultivation technologies, Agricult. Biolog. 5, 100-104 (2007)

5. V.A. Isaychev, N.N. Andreev, The influence of the liquid fertilizer blends on productivity of fodder barley, Bulletin of Ulyanovsk State Agricult. Acad., 4(40), 23-29 (2017)

6. V.A. Isaychev, V.I. Kostin, N.N. Andreev, Influence Of Macro And Microelements On Protein Producing
Capacity In Feed Barley Grain, Res. J. of Pharmac. Biology.l and Chem. Sci., 9(3), 1473-1477 (2018)

7. V.G. Vasin, A.V. Vasin, A.N. Burunov, N.V. Vasina, O.P. Kozhevnikova, Influence of soil tillage, fertilizers and biostimulants on the yield of spring wheat in the forest-steppe of the Middle Volga, IOP Conf. Ser. Earth and Environmental Sci., 422(1), 012017 (2020)

8. V.G. Vasin, A.N. Burunov, A.V. Vasin et al., Microfertilizer mixture megamix application on spring wheat, Res. J. of Pharmac., Biolog. and Chem. Sci., 9(5), 1248-1260 (2018) 